\title{
Promoting sustainable development of poverty-alleviation policies based on high-quality cultural tourism by digital economy - A case study of Chishui City in Guizhou Province
}

\author{
Fawen Yang ${ }^{1, a}$, Cheng Yang ${ }^{1, b^{*}}$, Qian Xie ${ }^{2}$ \\ ${ }^{1}$ Postdoctoral research fellow in College of Ethnology and Sociology,Southwest Nationalities Research Institute of \\ Southwest Minzu University and Lecturer of Southwest Minzu University; Lecturer of Sichuan Police College; \\ Cheng Du of China ;610041. \\ ${ }^{1}$ Lecturer of Southwest University of Political Science and Law.PhD. of Zhongnan University of Economics and \\ Law. \\ ${ }^{2}$ Appointed government official for poverty-alleviation initiative in Chishui City, Guizhou, China.
}

\begin{abstract}
Digital economy follows three laws - the Metcalfe's law, the Moore's law, and the Davidow effect, which are practically in line with China's poverty-alleviation initiative by developing cultural tourism. The Moore's law, however, is paradoxical in given contexts, and thus, we proposed the "reverse-Moore's law" to analyze the current cultural tourism-based poverty-alleviation policies. The features of digital economy can be employed to support the cultural tourism-based poverty-alleviation work; the development trend of digital economy also coincides with China's cultural tourism-based poverty alleviation initiatives. With the poverty-alleviation work at Chishui City in Guizhou Province as the study case, this paper made an analysis from the perspective of digital economy to confirm the practical and surreal significance of applying digital economy to China's poverty alleviation endeavors.
\end{abstract}

\section{Introduction}

Digital economy, in a strict sense, is an economic concept that refers to a process in which the big data is detected, selected, filtered, stored, and utilized to optimize allocation and regeneration of resources to realize high-quality economic growth [1]. Digital economy is developed using the ever-evolving information tools like Internet facilities and intelligent terminals, and based on the Internet-cloud computing-blockchain- Internet of things technologies; as people's big data processing skills improve, the economy has evolved from industrial economy, information economy, knowledge economy to intelligence economy, which reduces the trading cost and maximizes the efficiency of resource allocation optimization to increase the added value of products, enterprises and the industry, advance the social productivity, and lay a technical foundation for the underdeveloped countries and regions to catch up and make breakthroughs. It is because of the benefits of digital economy that China manages to make stunning breakthroughs in diverse fields [2]. The digital economy is subject to the three economic laws, boasts five features and three advantages. If these attributes of digital economy can be organically incorporated into research on tourism-based poverty-alleviation policies, it is expected to make substantial advancements.

\section{Matching between the three economic laws of digital economy and cultural tourism-based poverty alleviation initiative}

\subsection{The Metcalfe's law}

The Metcalfe's law states that the effect of a telecommunications network is proportional to the square of the number of connected users of the system. The value of a network is equal to the squared of the number of nodes in the network, i.e., $\mathrm{V}=\mathrm{n}^{2}$ (where $\mathrm{V}$ is the value of the network, and $\mathrm{n}$ is the number of network users). To 
put it another way, the more connected computers and terminals there are in a network, the higher the value of the network is. This theory assumes that every terminal (user) enjoys the same value in the network, and thus the more terminals (users) there are in a network, the higher value the network has. For instance, if there are $n$ users (terminals) in a network, the value of the network to a user is proportional to the number of other users in the network, and thus is proportional to the total value of the network to all users (terminals), i.e., $V=n \times(n-1)=n^{2}-n$. If the value of a network to each user (terminal) is 1 yuan, then the total value of a network ten times of the scale will be 100 yuan, and that of a network 100 times of the scale will be 10,000 yuan. Thus, if the network grows ten times in scale (the number of users or terminals), the value of the network grows 100 times larger, presenting an exponential relationship.

To implement the cultural tourism-based poverty alleviation policies, we need first increase the popularity of the tourist sites to attract tourists, convert online visits to real trips to boost local consumption, advance local economic growth and lift the residents from poverty. To put it in terms of digital economy: the more online users the Internet brings, the more potential clients and trading customers there will be; there is a conversion process, and a higher conversion rate means a higher trading volume (called Internet traffic flow economy), and guiding the flow of users remains the key. In other words, a larger base of Internet users that receive information of the products ensures a larger conversion rate.

The Chishui city in Guizhou province is taken as the study case. Chishui, like Jinggangshan and Ya'an, is a well-known and time-honored city, and boasts advantages over tourist late comers like the Fenghuang ancient town in western Hunan, Lijiang and Dali in Yunnan. However, it is less famous than Jinggangshan and Yan'an. The brand of "Red Chishui" has not been made full use of. Though the tale of "Crossing the Chishui River Four Times" in the Long March is a household tale, few have been to the place, and Chishui is far less appealing than other tourist sites like Shangri-La and Zhangjiajie. In terms of digital economy, the reason is that not enough "nodes" have been deployed. A talk about Zhangjiajie will conjure up images of natural wonders; when it comes to Zhangjiajie, we think of the clubs and bars; when we talk about Chishui, however, we think only of the heroic endeavor of the Red Army crossing the Chishui River that we learnt decades ago in primary school, and few consider it a tourist site. As a result, few have the intention to visit the site of Chishui that we have only learnt about in primary school textbooks. In the network of cultural tourism, if the nodes are not deployed widely enough, few users will know about this site, leading to a small base of potential visitors and thereby a small conversion rate.

\subsection{Moore's law}

Moore's law is proposed by Gordon Moore, a co-founder of Intel. When the price is constant, the number of components available on an integrated circuit and the circuit's performance will double every 18 to 24 months. In other words, the performance of a computer bought by one dollar will double every $28-24$ months. Take the chips as an example: the processing capacity of a computer chip doubles every 18 months, but its price halves [3]. Research has revealed that a transistor is worth 10 dollars in the 1960s; and due to technological reform, the transistors become smaller, and when 1000 transistors can be place on one hair, the cost of each transistor is reduced to $1 / 1000$ dollar. By 100,000 multiplication, the IBM704 computer is worth 1 dollar, the IBM709 computer is worth only 20 cents, and the IBM360 computer that IBM developed at a cost of 5 billion dollars in the 1960s is worth only 3.5 cents. [4] This law, however, reveals only the speed of information technological progress, and cannot be considered a law or equation in the strict sense. Thus, some scholars have suggested that "though this trend has continued for half a century, but the Moore's law can only be an observation or inference method, but cannot be considered a physical or natural law" [5].

Moore's law provides an interpretation from the angle of developers and margin costs, but from the angle of the market and the consumers, or the investors, the reality is the contrary - the price of the processor rises as the computing capacity improves. Take Intel as an example. Ten years ago, Intel released a leading CPU "Core2D", priced at 224 dollars, which is equal to 1792 yuan by that exchange rate at that time. Ten years later, it released another CPU i9-7920X, priced at 1199 dollars, equal to 8058 yuan, and i9-7980XE, priced at 1999 dollars, equal to 13,435 yuan. Such examples can also be found in automobile and cell phone markets. It is proved that the price does not drop because of the improved processing capacity or performance; instead, the unit price and the overall return rise, for which we term as "reverse Moore's law". It is most obvious in the electronics industry. As the products upgrades quickly, and the increase in the cost of research and development will be counted into the final price. The Moore's law performs cost calculation after the success of research and development, but has not count in the primary cost for research and development. Based on the modern capital calculation method, the 5 billion dollars IBM invested into development of a CPU will be split onto each sold piece of product and thereby be taken back from the buyers.

Likewise, in cultural tourism, the output of single programs of a tourist site or the site's overall capacity will inevitably improve, but the price for the programs or the overall site will not fall. As per the first law of economics, the value equals the square of the number of nodes, so the number of users that know and use the terminals and the constant conversion rate become the key to improving income. That is the law that agrees with the digital economy and the reverse Moore's law. Therefore, if the concept of digital economy is introduced into cultural tourism, then the reverse Moore's law works in the following way: when the number of consumers does not increase or remains 
constant (as with the number of customers of electronic products remaining constant), the capacity and productivity improves, but the unit price will not fall and the overall income will increase. If the price remains relatively unchanged, the trading volume can be increased by increasing the programs or extending the stay of the customers, thereby increasing the overall income.

Unlike the electronic products, it is rather challenging to upgrade a tourist product, but increasing the tourist programs is not hard. For instance, Chishui City has initiated the Valley Music Festival in these years to invite musicians and stars for performances, and sold packet tickets to different sites. If tourist agriculture and medical herb cultivation bases are introduced to the tourist industry of Chishui, it will not only enrich the set of tourist programs, but extend the tourists' stay and thereby boost the consumption in hospitality and shopping in this area.

Yet, Chishui still has a long way to go in this regard. The authors have made fieldwork in Fuxing Wharf in Chishui, which is renowned as the Red Army's First Wharf across Chishui". The red stone steps and the wooden buildings are as they were in the old times, but the "small town" which is less than one hundred meters long is actually like a neighborhood, without many tourist facilities, and it takes no longer than half an hour to finish a tour in the town. Two problems thus emerge: first, the tourist mode is short of diversity and fails to appeal to tourists; second, the small scale of the site will definitely disappoint the tourists who travel thousands of miles to this place but finish the tour in just one glance. The Tucheng Town in the neighboring Xishui County, however, is far more successful as a red tourist site, and even holds appeal to the locals in Chishui. During the fieldwork in Chishui, the authors found that the locals would recommend the visitors for a trip in Tucheng Town, which provided a glimpse into the gap between the two cities.

\subsection{Davidow's effect}

Davidow's effect suggests that an enterprise must upgrade its product to survive in the industry. To dominate the market, an enterprise must be the first to develop a new product or a new generation of the product. In most cases, the first generation of a product will take up $50 \%$ of the total market share, so any enterprise will first phase out its own products in the market. This comprises of two parts. First, a new product occupies half of the total market share, and second, to take up the new market, an enterprise must phase out its own product and capture the market with an upgraded product; if the product is phased out by rivals, the enterprise will lose the $50 \%$ market share to others.

In the case of Chishui wharf, though other sites are also wharves, the wharf in Tucheng turns out the "first generation" that enters the market. The phenomenon that "the first gets the most attention" is prevalent in different fields, but late comers can also release new tourist products to capture a new market. For instance, Chishui has initiated the Velley Music Festival, and by dint of other famous tour spots like the Jurassic Park, the Chishui Waterfall, and Four Cave River, Chishui has developed the sightseeing agriculture with characteristic agricultural products like Dendrobium and bamboo groves. These new products that combine natural advantages and the human innovation can boost a new market of tourism.

Chishui is well-known across China because it marks a significant move in the Long March. The name of the city is a brand to capture the market, which turns out a natural blessing; in terms of geographic advantages, Chishui has many cultural relics, such as the ruins of dinosaurs and the Cyathea Kingdom, which are rare around the world. Also, Chishui tops the list in China in terms of the history and area for growth of Dendrobium (the largest festival for Dendrobium, however, is held in Hangzhou every year). That is to say, Chishui not only fails to seize the $50 \%$ market share, but also has not caught up with others to gain new market shares.

\section{Five features of digital economy and its combination with cultural tourism-based poverty alleviation initiatives}

\subsection{High efficiency}

The Internet has nearly removed all boundaries between countries and regions, and connects all countries and regions into a complete world, making the world into a "global village". From the proposal of "economic globalization", to development of "global village", and then to the realization of "a community with a shared future", all these concepts indicate that the world is moving towards globalization. Any information from any corner of the world can be spread to any other corners in this global village. The time cost for information transmission and economic exchange has be substantially reduced, which speaks to the high efficiency feature of digital economy.

Before the invention of Internet, information transmission is subject to limits of time and space, and the representation form is short of diversity. In the Internet age, however, digitalized information can be transferred with high fidelity to any node in the network, free from limits of time and space.

Digital economy is a form of efficiency-oriented economy. By dint of the information network, information can be delivered to any node in the network in a blink of an eye; in other words, the information in digital economy is collected, processed and used in real time. In digital economy, the receiver receives all required information efficiently, while the sender can receive feedback in real time, which greatly enhances the efficiency of exchange. Surely, the exchange circle will expand, because the circle of information transmission in digital economy has no limited radius; in other words, the radius of digital economy can be expanded indefinitely, and the nodes can be increased indefinitely. 
Cultural tourism also entails high efficiency. The operators need to deliver information of their products to potential customers and process the feedback of real visitors that are converted from the information receivers. In particular, in face of feedback that works against their brand reputation, the operator needs to adopt public relation measures to curb the spread of the negative information and maintain its reputation. Moreover, it is necessary to capture the market dynamics and follow the development trend of the market, such as the latest forms of tourist programs, adjust strategies to keep up with the times. The up-to-date tourist programs should be promoted promptly to appeal to users in different tour spots.

The world now is seeing changes of unprecedented breadth and depth. As high-tech develops in leaps and bounds, competition of comprehensive national power featured by informatization and information technology grows increasingly fierce. All these can be summarized by one adjective: fast. Both developed and developing countries make a point of digital economy boosted by information technology and consider it a priority of national development by advancing informatization.

\subsection{High permeability}

There are no industry boundaries in digital economy, and any goods can be traded on the Internet. The fast-developing information network technology high permeability and can integrate different industries. Take Tmall as an example. On Tmall, both consumers and the business owners can find the goods or the market they want. The information services have extended into the first, second and third industries, blurring the boundaries of industries and leading to integration of the three major industries.

The essence of digital economy is to turn goods and markets into digits and information. Specifically, the revolutions in production tools brought by computer and Internet have shifted industrial economy to information technology. This shift cannot be fulfilled by one single industry; rather, information technology should be introduced into different industries, such as the microelectronics industry, the communications equipment and devices manufacturing industry, computer hardware, information and data collection, processing, and storage[6]. Use of information technology should be introduced into different industries to, for instance, improve the productivity of the first, second and third industries. It will not only boost the manufacturing and service industries, but advance business activities, such as the "liquid mixture" that blends manufacturing with the service industry. In many developed countries, the information service industry has grown into the largest industry, and digital economy is the driving power of this industry.

Before the boom of digital economy, cultural tourism is developed by the traditional method of "waiting to be promoted", because the tour spot cannot be moved to other places, and it is hard for promotion. It can only wait for the visitors, which reduces the nodes and the conversion rate. In the digital economy era, the highly permeable Internet can diversify the tourist products, and enrich the forms of representation of tour spots. This will substantially increase the number of nodes, and ensure the conversion rate as there are no boundaries between industries.

\subsection{Self-expansibility}

The value of digital economy equals to the square of the number of nodes in the network, and the benefits brought about by the network will increase exponentially as the number of the network users increase. In digital economy, due to the universal psychological response and habits, the advantages or disadvantages of a system will be augmented, leading to monopolies in which "the strong becomes stronger, the weak becomes weaker, and the winner wins all".

This is not hard to understand. Digital economy moves everything onto the Internet, and turns the information into tangible data, making all products and services accessible and selective. In the past, the occupancy rate of a hotel, the consumption of a restaurant, the visitors a tour spot can hold are unknown to the public; the service providers, though eager to make these data public, find it challenging to update the data in real time and cannot see the immediate benefits. In this era of digital economy, the occupancy rate, how many rooms are still available, and the prediction of following days of a hotel are instantly available online. Customers can leave comments for the potential consumers and provide suggestions for improvement. Meanwhile, all information of a restaurant, such as the selling volume, the quality of food, the service quality, is public. For a tour spot, whether it is worth visiting can be shared by visitors.

In this way, digital economy reverses the owner-customer relation in the tourist industry, generating an "interactive" mode in the age of digital economy. "Gangster inns" or "ripping-offs" that used to plague the customers no longer exist; instead, the service providers improve the service quality and the customers' experience to win "mouth-by-mouth" reputation.

\subsection{Incremental margin benefits}

The increment of margin benefits is manifested in two aspects. The first is the degression of marginal cost of digital economy; the second is the increment of accumulative value of the digital economy.

Marginal cost and marginal benefits are pure economic concepts, and they will not be discussed further here. The degression of marginal cost of traditional economic modes will not exceed the degression of marginal cost of digital economy. The cost of traditional economy is material and physical investments; in digital economy, however, the cost is investments in the form of digits or virtual investments, and such cost is manifested by numbers of exponential scales or infinite scales. For example, if the inventory of a product on an online store shows 100,000 , it is just a 
number, not the actual pieces of products, and the production cost and storage cost will add to the marginal cost. Likewise, the increment of margin benefit of digital economy will exceed the marginal benefit of traditional economic forms[7].

In the industry of cultural tourism, the degression of marginal cost and the increment of marginal benefits are tangible, and the accumulative value increment of digital economy is obvious. The investments into construction of a tour spot and staffing are fixed, and the number of staff members is relatively fixed. In terms of the cost, an increment in the benefit will not increase the cost. This is different from the manufacturing industry, in which one piece of sold product will require production of a corresponding piece of product, leading to decrease in the marginal cost. In the same logic, one product in the cultural tourism can be sold multiple times, which will inevitably increase the marginal benefits. The combination between the reputation effect of cultural tourism and the node law in digital economy will quickly increase the accumulative increment of value.

\subsection{Sustainability}

Sustainable development is a national policy of China. Digital economy can, to the greatest extent, avoid excessive consumption of tangible resources and energy, environmental pollution and ecological degradation, thereby achieving sustainable development.

Development of many industries in history is at the cost of depletion of resources. Some rely heavily on supply of resources, such as the traditional energy industry. As the resources are used up, industries that cannot find alternative resources disappear, and only by adopting the sustainable development strategy can the industry survive. In this sense, digital economy has significant advantages over traditional economic forms[8].

One salient feature or advantage that cultural tourism has over other industries is that it is sustainable. In terms of resource consumption, constant resources outperform renewable resources, which outperform non-renewable resources. Cultural tourist resources are constant resources which does not reduce during consumption, and are even protected. The cultural tourist sites in Chishui, Guizhou are principally natural sceneries, such as the river crossing wharf, the Danxia landform, the waterfalls, the valley of Alsophila spinulosa. All these are sightseeing sites of natural beauty and are developed in a protective manner to avoid the phenomenon of "killing the goose that lays the golden eggs". Developing cultural tourism, in fact, is following the fundamental policy of sustainable development that "seeks both material wealth and environmental well-being".

\section{Matching between digital economy and three trends of cultural tourism}

\subsection{Speed has become the key competitive factor}

As mentioned before, high efficiency is one feature of digital economy, which means that it must respond more quickly to changes than the market to survive and grow. Changes in the market are hard to control, consumers' needs keep changing, rivals emerge one after another, and the updating cycle of the products and services becomes shorter and shorter ... .... All these need the enterprises to respond quickly to the market changes and make decisions, and all roles in digital economy, especially the product provider, must keep up with the pace of the market changes and build their own "digital platforms".

In cultural tourism, speed is manifested in two aspects: the first is the sending and spreading of information. Different from the electronics industry, cultural tourism is subject to seasonal changes, and early all tour spots have peak and lean seasons. Thus, the information of the tour spot must reach the node in the network before the peak season. Though this will be a repetitive year after year, it will be the best promotion campaign before the spot becomes the "must-go" place for everyone.

The second is the speed of product upgrading. Unlike electronic products, tourist sites cannot be updated. That is not to say that cultural tourism has to stick to what it has until it loses appeal to the tourists. New entertainment programs can be introduced to "upgrade" the tour spot. The Internet celebrity economy manifested by Internet hit cities, Internet hit sceneries are good examples in the tourism industry that have grasped the essence of speed. When one tourist program loses appeal, another new and hot one step in place to ensure information flow and visitor flow. This is also a form of product upgrading.

The third is the capacity (efficiency) of the tour spot. For example, some tourists have bad experience in the ticketing service, the welcoming service, hospitality, the restaurant service, sightseeing, because the capacity of the tour spot is not enough. Charing the visitors for the services that fall short of their expectation seems lucrative, but it pays a price in the long run. In the age of digital economy, all information about the ticket, the hotel and the restaurant are available online, all appointments can be made in a click and tourists can scan the QR code to enter the tour spot instead of waiting long in the sun. If other measures can also be made to increase the capacity of the site and improve the tourist experience, the local economic efficiency will increase.

\subsection{Cross-industry collaboration becomes an inevitable choice}

As mentioned before, the second feature of digital economy is high permeability. The massiveness of the market (often termed the "cake"), the diversity of products, the intensity of market competition prompt enterprises to cooperate and share resources to take an advantageous position. For instance, the rapid development of the delivery service industry is because the market expands while no one single enterprise can 
fulfill all roles. Market expansion leads to generation of the scale economy, and the massive investment and risks also drive enterprises to cooperate to share the cost. Then, for any participant in the market, except the consumers, no matter what role they paly will cooperate amid competition to minimize the cost while maximizing the profit.

Information technology, especially Internet technology, which lies in the heart of digital economy can minimize the cost of cooperation, making broad and low-cost cooperation possible. Collaborative partners generate virtual enterprises through information platforms, which have the massive resources that large enterprises have and also the flexibility typical of small enterprises, so such virtual enterprises have a larger chance than their traditional counterparts to survive and grow in the market competition.

In the case of cultural tourism, before the invention of digital economy, many industries are independent from each other and compete with each other, but in the age of digital economy, this pattern is overthrown. The tourist sites, restaurants, hotels, agricultural products and medical herbs production sector in a tour spot are integrated. The central idea in the age of digital economy is "Internet flow", which can be converted into tourist flows. People nowadays do not aim at one single destination for a trip. With enough time and money, they tend to "tick off" the famous spots when going to one place. In this context, the best solution to the tourist spot operators and other service providers is to cooperate to improve tourist experience. Such cooperation will not only increase the tourists' intention to visit again, but reach more potential tourists, leading to a virtuous cycle in which everyone benefits.

\subsection{Large-scale "customized services" become possible}

In traditional economy, we are accustomed to "standardized" and "unified" products and services, but the age for "unified" products and services has already passed, and people now are seeking for uniqueness. Generalized products are identikit, and the age in which customized products are available only for the few has passed - digital economy has overturned the traditional tenet. With the support of information technology, enterprises can collect and analyze customer information and demand with the low cost, and provide customized products or services with flexible and controllable production system. Products or services of different scales - villas, cars, shoes and shirts can be customized, and we have benefited from the customized products and services the digital economy brings unwittingly.

When customization has not been prevalent in tourism in China, it has already gained popularity in the Europe and America. When studying in the U.S., the author has enjoyed customized services, which are not expensive but really considerate. Customized services like chauffeuring services, 24-hour steward service, free selection of tour spots, self-decided arrangement of schedules, are so different from group trips in which one has to follow the group and visit places that one does not intend to. A customized trip is relaxing and does not engage the tourists in unnecessary detours or distractions.

Most trips in China are group trips, and only a few are self-driving tours. The latter often has constraints on the cost, time and number of tourists. $90 \%$ of the self-driving tourists in China, however, are retired elders who have plenty of leisure time but are short of physical strength and find the self-help services hard to grasp. If we can provide "customized" services that cover airport pick-up, tour, dining, hospitality, cultural interpretation, tasting of local specialties, giving optimal experience to different tourists, the cultural tourism industry will develop independent of poverty alleviation policies.

\section{Conclusion: prospect of boosting cultural tourism by digital economy}

The U.S. has seized the opportunities in the digital revolution in the 1990s and enjoyed economic boom for over a decade that exceeds the achievement of half a century. In the $21^{\text {st }}$ century, European countries and Japan followed suit and also made splendid breakthroughs. Now, digital technology has reached maturity, so for developing countries, it means more about opportunities than about challenges and trials, and what matters is the upgrading of ideas. It is fair to say that digital revolution has brought about opportunities that are not available once in a blue moon. Digital economy can allow developing countries to make use of their advantages as late comers and narrow their gap with developed countries. It has great prospects to boost cultural tourism by digital economy.

The features of digital economy indicate that the benefits in the innovation stage will exceed the returns in the later popularization stage. The thirty years of developing countries to promote digital economy will reduce the marginal benefits; while in developing countries, digital economy is a nascent industry and is in the stage where the U.S. experiences thirty years ago, so developing countries will maintain large marginal benefits. For developing countries, digital economy means the latest and most innovative knowledge and technology. The digital economy of developed countries is now introduced into developing countries by simulation or copying of technologies. In this way, developed countries can benefit from transferring advanced technologies to developing countries, and developing countries can seize the opportunities to achieve the goal of informatized development. When these two are organically integrated, the marginal benefits of developing countries will increase in the long run, laying a foundation for sustainable development of digital economy.

There is no denying that industrial revolutions are the engine that drives forward the whole society. The Western countries enter the age of information with the wealth accumulated in industrial revolutions. For the whole human world, we have benefited from industrial revolutions. The digital revolution will be like the 
industrial revolutions that drive the world forward. Developing countries have skipped the long experimental stages like the industrial revolutions to make use of technical and policy achievements of industrial and digital revolutions made by developed countries, thereby accelerating economic and social progress. This process can be interpreted by a vivid metaphor: the journey that developed countries take from industrial revolution to digital revolution is like a marathon that takes much time and energy; for developing countries, it is like a relay race and they can make use of the development results already achieved by developed countries. After all, knowledge, as the cornerstone of development of the human society, inevitably benefits all.

In the age of digital economy, countries or enterprises can spare extra time, technology and management methods to develop diverse industries, liberate the entrenched thinking styles, and combine different industries with information and digital industries, to promote the development of hi-tech industries in return, revolutionize the traditional industries, and develop their own advantages. Besides, when digital economy reaches a certain scale, it can be integrated into relevant industries. For instance, based on digital economy, a country can boost logistics, manufacturing and the third industries, and thereby pushing the market towards prosperity.

China is the world's biggest developing country, with a large base of potential consumers. Developed countries shift industries to developing countries partly because the latter has cheap labor, and partly because the latter promises a massive market and a great potential demand of consumption. In particular, since the start of the new century, many developing countries, due to their large population and fast economic growth, have become promising markets that developed countries compete for. If the large base of resources in developing countries can be combined with the technology and network resources of digital economy, it can boost the economic growth of diverse industries.

The developing countries boast advantages in resources. Take cultural tourist resources as an example. China, with a vast area and long history, is one of the four oldest civilizations and boasts rich tourist resources. Regarding the matching between the market and resources, inner-bound production and sales have reached a considerable scale. During the May Day holidays and National Day holidays each year, about one billion tourists go out for trips, and the number of domestic tourists except the foreign visitors has already topped the list of tourists around the world. China now has unmatchable advantages over countries in terms of the market and the tourist resources.

This year is the year that evaluate the performance of the poverty alleviation initiative and a year to achieve the goal of "building a well-off society in an all-round way" in the $21^{\text {st }}$ century, and the next goal is to build an affluent society. The geographic features and resource distribution of China leads to unbalanced economic growth and economic specialties in different regions. Many regions have been lifted from poverty by dint of cultural tourism, and this mechanism of "making use of local resources to achieve affluence" relies on digital economy to develop further. Meanwhile, relevant industries should keep up with the times and embrace digital economy; the local governments should keep abreast of the times and release favorable policies to boost digitalized cultural tourism.

Currently, nearly all industries in developed countries have been digitalized. From agriculture to industry, from schools to farm fields, from aerospace to daily lives, digital technology has penetrated every aspect. Developed countries have enjoyed benefits from digital economy and the people have been provided with much convenience. In the future, more and more digital revolutions will refresh our entrenched ideas and the human world will reach an unprecedented level. Digital economy will become the dominating economic mode in the world in the long run. Developing countries need to learn and use this tool to reverse the situation and improve their productivity and comprehensive national power.

\section{Acknowledgment}

This work was supported by Mountain Economic Development Research Center of Minzu in Si Chuan(SDJJ2022); Doctor' s Research Fund of Sichuan police college in China (646000), Research on the Influence of Farmer Specialized Cooperatives on Rural Revitalization (2018YJBSQD25).

\section{References}

1. Chen Shiqing: " The glossary of Symmetric economics", Guangming Net, 2019-08-28 .

2. Chen Shiqing: " The glossary of Symmetric economics(one)", Guangming Net, 2019-08-28 .

3. Zhou Su, Wang Shuoping:" Big data era management information system", China Railway Publishing House, 2017, p120.

4. Yang Yilin:"Integral advertising science and economics", China Times Economics Publishing House, 2014, page 112.

5. Wan Min, Wang Zhenyou: "Introduction to Computer", Beijing Institute of Technology Press, 2016, page 4 .

6. Wang W. L., Wang J. Development trend and promoting policies of digital economy in China. Economic Review, 2019. 04.

7. Luo C. Z. Advantages of innovative digital industries and new patterns of integration of cultural tourism. Annual Research Report on Cross-Strait Creative Economy, 2018. 06.

8. Feng J., Ma L., Gao D. H. Precise marketing of tourist integration in Yinchuan in the age of digital economy. Journal of Ningxia University (Humanities and Social Sciences Edition), 2019. 03. 